\title{
Changes in Body Weight, Dysglycemia, and Dyslipidemia After Moderately Low-Carbohydrate Diet Education (LOCABO Challenge Program) Among Workers in Japan
}

\author{
Satoru Yamada $\mathbb{D}^{1,2}$ \\ Gaku Inoue' \\ Hisako Ooyane ${ }^{3}$ \\ Hiroyasu Nishikawa ${ }^{4}$ \\ 'Diabetes Center, Kitasato Institute \\ Hospital, Tokyo, Japan; ${ }^{2}$ Department of \\ Research and Development, The Eat, Fun, \\ and Health Association, Tokyo, Japan; \\ ${ }^{3}$ Corporate Strategy and Planning \\ Division, Health and Wellness Promotion \\ Committee, Lawson, Inc, Tokyo, Japan; \\ ${ }^{4}$ Planning Department, Hinomaru Kotsu \\ Co., Ltd, Tokyo, Japan
}

Purpose: It is theorized that the prevalence of obesity has not decreased owing to poor adherence to implemented programs addressing metabolic syndrome, obesity, and diabetes in Japan. Therefore, we intended to evaluate the influence of a moderately low-carbohydrate diet on improving markers of metabolic syndrome among workers in Japan.

Patients and Methods: Participants with metabolic syndrome or obesity were recruited based on the eligibility criteria for the Specific Health Guidance program and educated on a moderately low-carbohydrate diet between spring 2016 and fall 2018. The participants were then made to report their food intake and body weight once a week for the next 12 weeks and were counselled on maintaining a moderately low-carbohydrate diet. HbA1c levels, lipid profile, body weight, and sleep quality were evaluated. The normality of the data was evaluated using the Skewness/Kurtosis test. Each variable was compared before and after the intervention using the Wilcoxon signed-rank test. Further, a subgroup analysis of the data from the participants whose variables were abnormal at baseline was performed.

Results: Among the 101 enrolled participants, a decrease in the median weight (from 82.5 to $79.7 \mathrm{~kg}, \mathrm{p}<0.001, \mathrm{n}=46$ ), body mass index (from 27.3 to $26.9 \mathrm{~kg} / \mathrm{m}^{2}, \mathrm{p}<0.001, \mathrm{n}=46$ ), and apnea-hypopnea index (from 24.1 to $17.1, \mathrm{p}<0.01, \mathrm{n}=39$ ) was observed. Subgroup analysis of participants with abnormal baseline values revealed changes in HbAlc (from $6.7 \%$ to $5.8 \%$, $\mathrm{p}<0.001, \mathrm{n}=34$ ), total cholesterol (from 220 to $209 \mathrm{mg} / \mathrm{dL}, \mathrm{p}<0.01, \mathrm{n}=54$ ), low-density lipoprotein cholesterol (from 133 to $120 \mathrm{mg} / \mathrm{dL}, \mathrm{p}<0.001, \mathrm{n}=31$ ), high-density lipoprotein cholesterol (from 35 to $40 \mathrm{mg} / \mathrm{dL}, \mathrm{p}<0.01, \mathrm{n}=31$ ), triglycerides (from 242 to $190 \mathrm{mg} / \mathrm{dL}$, $\mathrm{p}<0.01, \mathrm{n}=57$ ), and deep sleep percentage (from $10.4 \%$ to $18.2 \%, \mathrm{p}<0.05, \mathrm{n}=7$ ).

Conclusion: A moderately low-carbohydrate diet may be considered a potential intervention for improving the markers of metabolic syndrome, obesity, and diabetes.

Keywords: metabolic syndrome, moderately low-carbohydrate diet, obesity, overweight, Japan

\section{Introduction}

Metabolic syndrome (MetS), obesity, and diabetes are simultaneous global epidemics. ${ }^{1,2}$ Previous studies have suggested that lifestyle interventions can effectively reduce body weight, prevent the onset of diabetes, and improve blood

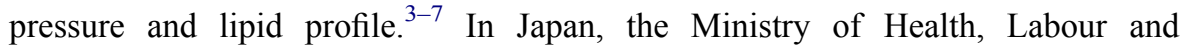
Welfare started the Specific Health Checkup and Specific Health Guidance projects 
in 2008 to reduce and/or treat MetS. ${ }^{8}$ The Specific Health Checkup includes annual laboratory tests, questionnairebased health assessments, and physical examination to evaluate MetS risk. The Specific Health Guidance includes advice on energy restriction and physical activity (see Supplementary Materials) and was developed for high risk participants. As these interventions are recognized as complicated and challenging to adhere to, face-to-face individual behavioral counseling is recommended. ${ }^{9}$ Although preliminary evaluation studies have reported that the participants of the Specific Health Guidance program achieved body weight reduction (on average, $1.98 \mathrm{~kg}$ for men and $2.25 \mathrm{~kg}$ for women) and improvement in plasma glucose, blood pressure, and lipid profile; ${ }^{10,11}$ a recent large-scale evaluation revealed no association between the Specific Health Guidance and clinically meaningful weight loss or improvement of other cardiovascular risk factors. ${ }^{12}$ The Specific Health Guidance involves lifestyle interventions such as energy restriction and encouragement of physical activity, which are perceived as troublesome and difficult to maintain. ${ }^{13,14}$ This suggests that novel methods of effective implementation are needed. ${ }^{11,15}$ Therefore, we developed a novel 3-month intervention program, consisting of non-energy-restricted moderately low-carbohydrate diet education only. ${ }^{16} \mathrm{We}$ named the diet (roughly 70-130 g/day of carbohydrate intake) LOCABO, and the evaluation program the LOCABO challenge. LOCABO has a target carbohydrate content of 20-40 g per meal. Furthermore, consuming confectionary amounting to $10 \mathrm{~g}$ of carbohydrates per day was permitted, resulting in a total carbohydrate intake goal of $70-130 \mathrm{~g} /$ day. ${ }^{16-18}$

Recently, Hyde et al compared low ( $45 \mathrm{~g} /$ day), moderate (234 g/day), and high ( $420 \mathrm{~g} /$ day) carbohydrate diets in a 4-week crossover study. In this feeding trial, a lowcarbohydrate diet appeared superior to a moderate- and high-carbohydrate diet at reversing MetS. ${ }^{19}$ However, Johnston et al have reported that a ketogenic diet $(<50 \mathrm{~g} /$ day of carbohydrates) yields no metabolic advantage over a non-ketogenic low-carbohydrate diet. $^{20}$ Although the reasons for the difference between these two studies are unclear, one of these may be the difference in the study design: one was a feeding study ${ }^{19}$ and the other did not include feeding. ${ }^{20}$ In fact, Harvey et al have reported that adherence to the allocation of carbohydrate was more easily achieved in moderately low-carbohydrate diet and low-carbohydrate diet groups compared to the ketogenic diet group. ${ }^{21}$ Furthermore, Li and Heber commented that following a ketogenic diet requires the supervision of a physician and a registered dietitian. ${ }^{22}$ Given these considerations, we decided to retain the carbohydrate intake within a lower limit to prevent ketogenesis ( $>20 \mathrm{~g} / \mathrm{meal})$ and remain consistent with the definition of a lowcarbohydrate diet $(<130 \mathrm{~g} /$ day $){ }^{23,24}$ The aim of this study was to evaluate the influence of the LOCABO challenge on improving the markers of MetS. To the best of our knowledge, this is the first study to evaluate the influence of moderately low-carbohydrate diet education incorporated into an intervention for MetS traits, such as overweight, dysglycemia, and dyslipidemia, in Japan. As MetS has also been known to have a bidirectional relationship with sleep apnea, ${ }^{25}$ we also evaluated sleep quality in this study.

\section{Patients and Methods \\ Participants}

This was a 12-week interventional cohort study. The study cohort was recruited from two companies, Hinomaru Kotsu Co. Ltd, which is one of the largest taxi companies in Tokyo, and Lawson Inc., one of the largest convenience store chains in Japan. As an interventional method similar to the Specific Health Guidance, the companies adopted the LOCABO challenge for their taxi drivers and convenience store staff. Recruitment took place twice per year, and each round enrolled 10-30 participants. The upper limit on the number of participants (30) was set based on our capacity to maintain effective communication between the participants and study staff. Between spring 2016 and fall 2018, a total of six recruitment rounds took place, involving taxi drivers and convenience store staff who are shift workers and had difficulty in maintaining regular eating and exercise habits. The participating companies identified workers who were interested in the LOCABO challenge through office posters and intranet magazines. They were then included in the study based on the eligibility for the Specific Health Guidance program. To eliminate the effect of medication on the study results, subjects who took antidiabetic and antihyperlipidemic drugs were excluded from this study. The inclusion criteria of this study has been detailed separately and provided as Supplementary Materials. This study was approved by the Institutional Review Board of the Kitasato Institute Hospital (Approval Study No. 18049). The study was performed in accordance with the Declaration of Helsinki. All participants were informed about the risks, benefits, and aims of the LOCABO challenge and were 
informed that they could withdraw at any time without any consequence. To prevent pressure from employers, participants provided their consent as part of their first food intake record.

\section{Sample Size Calculation}

Based on the findings of our previous study, we anticipated a change in HbAlc level of $0.6 \pm 0.0 \%$ in participants with diabetes. ${ }^{16}$ Furthermore, we anticipated a dropout rate of $20 \%$. Considering these factors, we required 92 participants, while ensuring that the study meets the following parameters: $\alpha=0.05$, power $=0.90$, and correlation $=0.40$. Therefore, we decided to recruit participants over 3 years (6 enrollment rounds), from spring 2016 to fall 2018.

\section{Education Schedule}

The LOCABO challenge began with an on-site seminar about the effectiveness, safety, and dietary pattern of the LOCABO diet. In this 60-minute seminar, we explained to the participants the burden of diabetes and MetS, showed them the results of our previous trial, ${ }^{16}$ and discussed food selection, including introducing restaurants that had LOCABOcompliant menus. Subsequently, participants were asked to record their food intake and body weight self-measurements and either email or fax these records to the study team every week for 12 weeks. The study team subsequently reviewed the participants' records and responded with comments or suggestions on the same sheet, within 3 days. The participants were advised to maintain their habitual physical activity and asked not to initiate any medication for diabetes and hyperlipidemia during the 12-week study period. Details of the seminar can be found in the Supplementary Materials, and the design of the study in the Figure 1.

\section{Measurement and Evaluation of Variables}

At the first and final session, we prepared a Specimen Measurement Office, ${ }^{26}$ where we measured participants' hemoglobin $(\mathrm{Hb}) \mathrm{A} 1 \mathrm{c}$ and lipid profile (Cobas b101, Roche Diagnostics Japan, Tokyo) using fresh capillary blood. We evaluated the change in HbAlc and lipid profile (total cholesterol [TC], low-density lipoprotein cholesterol [LDL-C], high-density lipoprotein cholesterol [HDL-C], and triglycerides [TG]) of all the participants. We evaluated the body weight and BMI data of the 46 participants who allowed to measure their body weight at baseline and in the final session. Furthermore, in trials conducted in 2016, we introduced a home-based sleep apnea test using a sleep-monitoring machine (WatchPAT, Philips Japan, Inc., Tokyo). WatchPAT can continuously measure oxygen saturation through pulse oximetry $\left(\mathrm{SpO}_{2}\right)$ and sleep stage through heart rate, and thus, is able to evaluate the apnea-hypopnea index (AHI), the lowest $\mathrm{SpO}_{2}$, and deep sleep percentage. The reliability of WatchPAT is well established. ${ }^{27}$ In this study, we did not

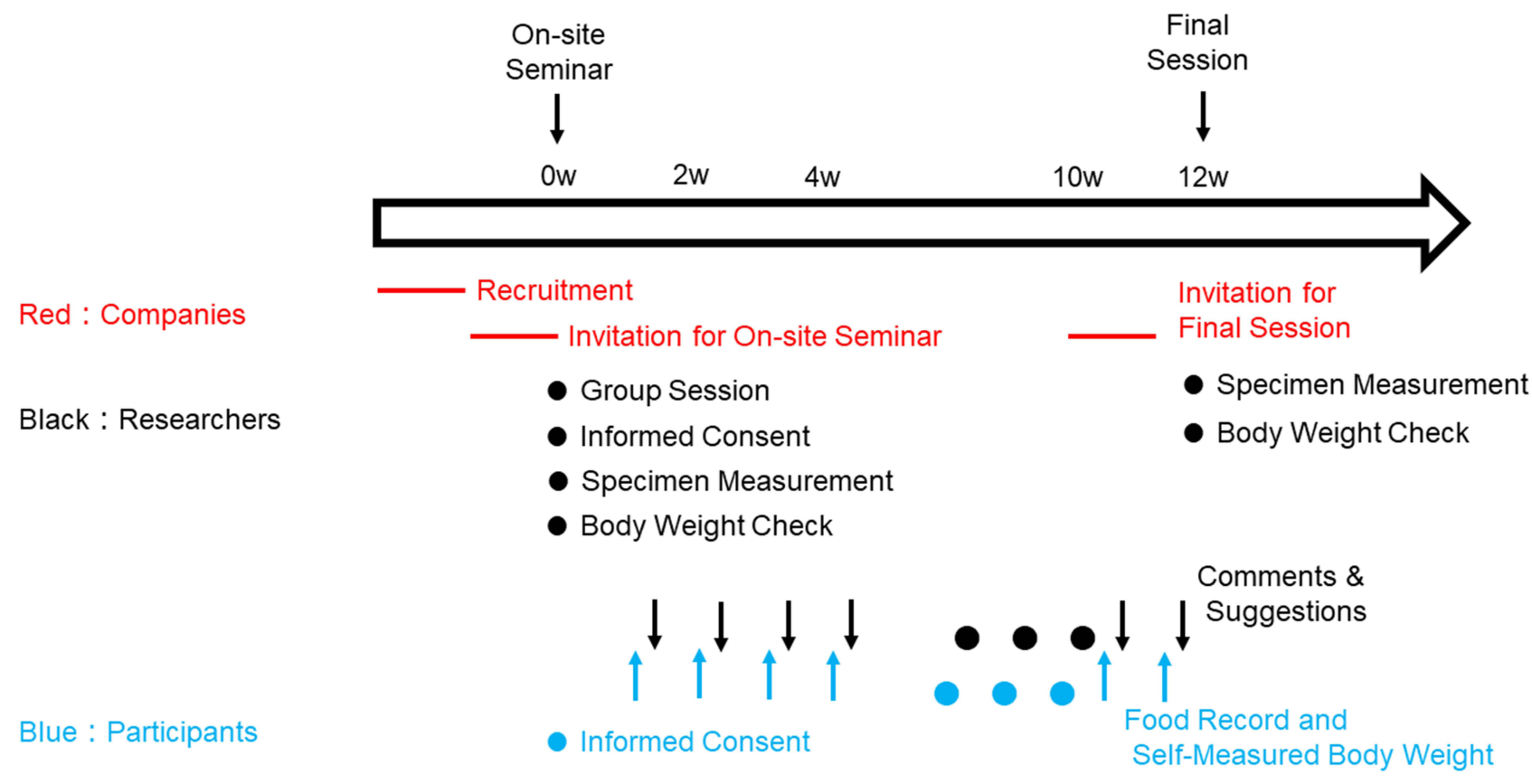

Figure I Schematic study design. Each participant provided a record of the food consumed by them and the researchers responded to them with comments and suggestions every week during the study period. 
calculate energy and macronutrients intake using food record and did not evaluate adherence to LOCABO because our education to limit carbohydrate intake was not an aim but was rather a method to improve subjects' outcome.

\section{Statistical Analysis}

The normality of the data was evaluated using the Skewness/Kurtosis test. Since all variables except LDL$\mathrm{C}$ were not normally distributed, we compared each variable before and after intervention using the Wilcoxon signed-rank test. For each variable, statistical procedures were based on complete before and after values. We performed a subgroup analysis of the data from the participants whose variables were abnormal at baseline: HbAlc $\geq 6.0 \%$ or $\geq 5.6 \%$, TC $\geq 200 \mathrm{mg} / \mathrm{dL}$, LDL-C $\geq 120 \mathrm{mg} / \mathrm{dL}$, HDL-C $<40 \mathrm{mg} / \mathrm{dL}, \quad \mathrm{TG} \geq 150 \mathrm{mg} / \mathrm{dL}$, BMI $\geq 25 \mathrm{~kg} / \mathrm{m}^{2}$, AHI score $\geq 5$, lowest SpO2 <90\%, and deep sleep percentage $<13 \%$. We performed statistical analysis using STATA version 13 (StataCorp LLC, TX, USA). The significance level for statistical tests was set at $p<0.05$.

\section{Results \\ Blood Tests}

We enrolled 101 participants during 2016-2018. No adverse event or change in medication was reported during the LOCABO challenge. The results of the whole cohort are shown in Table 1. There were no significant changes in any of the variables of interest (HbA1c, TC, LDL-C, HDL-C, and TG). However, subgroup analysis of the data from the participants whose variables were abnormal at baseline revealed significant changes in all variables of interest (Table 2). In particular, participants with $\mathrm{HbAlc}$ $\geq 6.0 \%$ at baseline showed a reduction in median $\mathrm{HbAlc}$ from $6.7 \%$ to $5.8 \%(z=3.958 ; p=0.0001)$.

\section{Anthropometric Measurements}

The median body weight and BMI reduced from $82.5 \mathrm{~kg}$ and $27.3 \mathrm{~kg} / \mathrm{m}^{2}$ to $79.7 \mathrm{~kg}$ and $26.9 \mathrm{~kg} / \mathrm{m}^{2}(\mathrm{z}=4.628$ and $\mathrm{z}=4.645 ; \mathrm{p}<0.0001$ ), respectively (Table 1). The mean body weight change was $3.55 \pm 4.42 \%$, with a median of $3.64 \%$ (quartile range $5.68-0.77 \%$ ) reduction. Among the participants with a BMI $\geq 25 \mathrm{~kg} / \mathrm{m}^{2}$ at baseline, the average body weight and BMI reductions were comparable with the reduction reported for the whole cohort (Table 2).

\section{Sleep Study}

The 2016 sleep study involved 40 participants. Data from one participant could not be included due to problems with equipment. Thus, data from 39 participants were evaluated, revealing a significant change in the AHI score (from 24.1 to $17.1, \mathrm{z}=2.610 ; \mathrm{p}=0.0091$ ) (Table 1 ). When we selected participants with abnormal values at baseline, statistical analysis also revealed a significant improvement in the deep sleep percentage (from $10.4 \%$ to $18.2 \%$, $\mathrm{z}=2.366 ; \mathrm{p}=0.018$ ) (Table 2).

Table I Measurements Before and After 12 Weeks of Following a Moderately Low-Carbohydrate Diet (Median [Quartile])

\begin{tabular}{|c|c|c|c|}
\hline Biomarker & Baseline & End of Study & $p$-value* \\
\hline \multicolumn{4}{|l|}{ Blood Test $(n=101)$} \\
\hline HbAlc (\%) & $5.7(5.4-6.0)$ & $5.6(5.4-5.9)$ & n.s. (0.39) \\
\hline TC (mg/dL) & $203(182-222)$ & $198(168-219)$ & n.s. $(0.054)$ \\
\hline LDL-C (mg/dL) & $106(93-126)$ & $106(86-129)$ & n.s. $(0.11)$ \\
\hline HDL-C (mg/dL) & $48(38-6 I)$ & 47 (39-59) & n.s. $(0.14)$ \\
\hline TG (mg/dL) & I 78 (| | 7-278) & $157(1 \mid 4-236)$ & n.s. $(0.73)$ \\
\hline \multicolumn{4}{|l|}{ Body Weight $(n=46)$} \\
\hline Body weight (kg) & $82.5(72.8-88.0)$ & 79.7 (71.9-85.9) & $<0.001$ \\
\hline BMI $\left(\mathrm{kg} / \mathrm{m}^{2}\right)$ & $27.3(25.9-28.8)$ & $26.9(24.8-28.6)$ & $<0.001$ \\
\hline \multicolumn{4}{|l|}{ Sleep Study $(n=39)$} \\
\hline Apnea-hypopnea index & $24.1(10.6-40.9)$ & I7.I (8.2-28.8) & $<0.01$ \\
\hline Lowest SpO2 (\%) & $84(78-88)$ & $84(79-88)$ & n.s. $(0.24)$ \\
\hline Deep sleep percentage (\%) & $17.0(15.4-22.7)$ & $19.1(15.2-24.0)$ & n.s. $(0.73)$ \\
\hline
\end{tabular}

Note: *Wilcoxon signed-rank test.

Abbreviations: TC, total cholesterol; LDL-C, low-density lipoprotein cholesterol; HDL-C, high-density lipoprotein cholesterol; TG, triglyceride; SpO2, oxygen saturation through pulse oximetry; n.s., non-significant. 
Table 2 Measurements Before and After 12 Weeks of Following a Moderately Low-Carbohydrate Diet in the Subgroup with Abnormal Results at Baseline (Median [Quartile])

\begin{tabular}{|c|c|c|c|}
\hline Biomarker & Baseline & End of Study & $p$-value* \\
\hline \multicolumn{4}{|l|}{ Blood Test } \\
\hline HbAlc (\%) $(\geq 6.0)(n=34)$ & $6.7(6.0-7.6)$ & $5.8(5.5-6.3)$ & $<0.001$ \\
\hline $\mathrm{HbAlc}(\%)(\geq 5.6)(n=60)$ & $6.0(5.7-6.8)$ & $5.6(5.5-6.0)$ & $<0.001$ \\
\hline TC $(\mathrm{mg} / \mathrm{dL})(\geq 200)(\mathrm{n}=54)$ & $220(206-230)$ & $209(192-225)$ & $<0.01$ \\
\hline LDL-C (mg/dL) $(\geq \mid 20)(n=31)$ & $133(125-149)$ & $120(102-136)$ & $<0.001$ \\
\hline HDL-C (mg/dL) $(<40)(n=31)$ & $35(30-38)$ & $40(33-44)$ & $<0.01$ \\
\hline TG $(\mathrm{mg} / \mathrm{dL})(\geq 150)(\mathrm{n}=57)$ & $242(191-367)$ & $190(134-285)$ & $<0.01$ \\
\hline \multicolumn{4}{|l|}{ Body Weight (BMI >25) $(n=37)$} \\
\hline Body weight (kg) & $85.0(80.5-89.7)$ & $83.0(77.2-87.0)$ & $<0.001$ \\
\hline BMI $\left(\mathrm{kg} / \mathrm{m}^{2}\right)$ & $28.0(26.7-30.4)$ & $27.2(25.7-28.7)$ & $<0.001$ \\
\hline \multicolumn{4}{|l|}{ Sleep Study } \\
\hline Apnea-hypopnea index $(\geq 5) \quad(n=34)$ & $25.1(|3.9-4| .6)$ & $17.2(\mid 1.8-28.8)$ & $<0.01$ \\
\hline Lowest SpO2 (\%) (<90) (n=34) & $84(78-86)$ & $84(79-88)$ & n.s. $(0.16)$ \\
\hline Deep sleep percentage $(\%)(<13)(n=7)$ & $10.4(0-12.2)$ & $18.2(13.0-22.2)$ & $<0.05$ \\
\hline
\end{tabular}

Notes: *Wilcoxon signed-rank test.

Abbreviations: TC, total cholesterol; LDL-C, low-density lipoprotein cholesterol; HDL-C, high-density lipoprotein cholesterol; TG, triglyceride; SpO2, oxygen saturation through pulse oximetry; n.s., non-significant.

\section{Discussion}

Previously, Riccardi and Rivellese proposed low-saturated fat, low-carbohydrate, and low-glycemic index diets for the dietary treatment of $\mathrm{MetS}^{28}$ Although recent American Heart Association guidelines recommend the replacement of saturated fat, ${ }^{29}$ several studies have described that the replacement of saturated fat with carbohydrates is associated with no improvement or even an increase in cardiovascular risk. ${ }^{30-32}$ Furthermore, a low-fat diet is recognized as a meaningless intervention for cardiovascular disease risk management. ${ }^{33}$ Thus, we evaluated a low-carbohydrate diet in this study. Furthermore, we did not adopt a ketogenic diet. Although Saslow et al have reported a ketogenic diet to be superior in comparison with a moderately low-carbohydrate $\operatorname{diet},{ }^{34,35}$ there are several reports of ketoacidosis in subjects without diabetes who follow a ketogenic diet. ${ }^{36-39}$ Following a ketogenic diet requires the supervision of a physician and a registered dietitian. $^{22}$ Thus, we adopted LOCABO.

In this study, LOCABO was associated with improving body composition and AHI scores. In addition, the HbAlc, lipid profile, and deep sleep percentage improved in participants with abnormal values at baseline. Importantly, for participants whose values of the aforementioned biomarkers were abnormal at baseline, the means of the postintervention results for HbA1c, LDL-C, HDL-C, and deep sleep percentage were all within the normal range, suggesting both a significant and a clinically relevant change. According to a previous report, ${ }^{40}$ a $2-4 \%$ body weight reduction corresponds to a $4-6 \mathrm{mmHg}$ reduction in systolic and diastolic blood pressure. Although this study did not measure blood pressure, it is theorized that the 3.55 $\pm 4.42 \%$ body weight reduction reported in this study may correspond to a proportional blood pressure reduction. These observations suggest that LOCABO is an effective method to treat and/or prevent MetS among Japanese workers.

The reason for stagnation in MetS prevalence in Japan is thought to be low participation in the Specific Health Guidance program. ${ }^{8-10,12}$ In our study, although the questionnaire was not an established one and the data were not shown, $50 \%$ of the participants felt that it was easy to follow LOCABO, while $68 \%$ found it easier to follow it compared to other dietary approaches they had previously attempted. These findings suggest that LOCABO is a suitable method for improving participation in the Specific Health Guidance program.

Recently, one Iranian group reported the association of low-carbohydrate diet score with cardiovascular risk factors and sleep status. ${ }^{41,42}$ According to this group, although low-carbohydrate diet score did not show statistically significant association with cardiovascular risk factors, ${ }^{41}$ there were associations with better sleep status. ${ }^{42}$ However, since their study had a cross-sectional 
design, further research will be needed to validate their findings.

The strength of our study is that this is the first study to show the influence of LOCABO in improving the biomarkers of MetS in Japan. Previously, a low-carbohydrate diet has been shown to improve glycemia. ${ }^{43}$ However, few studies to date have evaluated the effect of a lowcarbohydrate diet on the risk of developing MetS or diabetes. ${ }^{44}$ To the best of our knowledge, this is the first study to evaluate the influence of moderately lowcarbohydrate diet education on these outcomes in Japan, as well as to report the influence of LOCABO on sleep apnea and sleepiness. Recently, Shinoda et al have reported a $73.5 \%$ prevalence of sleep apnea in Japanese individuals with a BMI of $20-25 \mathrm{~kg} / \mathrm{m}^{2}$, and an $86.5 \%$ prevalence in Japanese individuals with a BMI of 25$30 \mathrm{~kg} / \mathrm{m}^{2}$ who also had diabetes. ${ }^{45}$ In our cohort (median BMI: $\left.27.3 \mathrm{~kg} / \mathrm{m}^{2}\right), 34$ among 39 (87.1\%) participants had sleep apnea (AHI score $>5$ ). Although MetS and diabetes are different conditions, their prevalence was similar in the present study. ${ }^{45}$ In the present cohort, the AHI score significantly improved (median change from 24.1 to 17.1), consistent with the improvement reported in a previous meta-analysis, where it was 6.04 in seven randomized clinical trials and 12.26 in nine before-after studies. ${ }^{46}$ To assess the changes in $\mathrm{SpO}_{2}$ and deep sleep percentage accurately, studies with larger samples are required to allow for age- and gender-stratified analysis. ${ }^{47}$

This study has some limitations. First, there was no control group; thus, we cannot exclude the possibility that factors other than LOCABO, such as counseling alone, also affected the results. Second, the sample size in the sub-analysis was small. Third, the participants had to apply to enroll in the study; this could have introduced a selection bias in the study sample because individuals who were more motivated to achieve changes in body weight, dysglycemia, and dyslipidemia, than the general population who were likely to enroll in the Specific Health Guidance program. However, $68 \%$ of participants felt that it was easier to follow LOCABO than other dietary approaches. In fact, we recently reported that LOCABO could maintain its effect on HbAlc improvement over 36 months ${ }^{17}$ and that even Michelin-star restaurants could serve moderately low-carbohydrate menus. ${ }^{48}$ These studies have shown that adherence to LOCABO may be relatively easy and that it may confer long-term health benefits. Selection bias is unlikely to have significantly affected the data, in particular, for the groups involving taxi drivers and convenience store staff. Fourth, the study duration of 12 weeks is short and we cannot rule out the seasonal change. The achievement rates of $\mathrm{HbAlc}$, blood pressure, and LDL cholesterol were lowest in winter and highest in summer. ${ }^{49}$ We recruited participants in spring and fall in this study. Thus, the influence of seasonal change must be limited. Finally, our study findings might have limited generalizability. In this study, dietary education was delivered by SY, who is accustomed to delivering low-carbohydrate diet education. However, in Japan, the majority of registered dietitians are not accustomed to it. Furthermore, Sato et al reported that weight reduction achieved with a moderately low-carbohydrate diet at 6 months was not maintained at 12 months. ${ }^{50,51}$ However, other studies have shown long-term improvement as a result of a moderately low-carbohydrate diet at $24^{52}$ and 36 months. ${ }^{17}$ Furthermore, a systematic review of studies involving patients with type 2 diabetes in Japan revealed that a moderately low-carbohydrate diet was superior to an energy-restricted diet. ${ }^{53}$ Thus, it is important that registered dietitians in Japan are able to adequately provide low-carbohydrate diet education.

\section{Conclusion}

LOCABO could be a potential intervention method for preventing and treating MetS. Japanese companies, health insurance associations, registered dietitians, and health care providers should recognize that consumption of a moderately low-carbohydrate diet could be a potential method to improve markers of health associated with MetS. Nevertheless, to confirm the present study findings, randomized clinical trials that compare the effects of a moderately low-carbohydrate diet and an energy restriction-based diet on MetS are needed.

\section{Ethics Approval and Informed Consent}

This study was approved by the Institutional Review Board of the Kitasato Institute Hospital (Approval Study No. 18049) and was performed in accordance with the Declaration of Helsinki. Informed consent was obtained from all participants involved in the study.

\section{Acknowledgments}

The authors thank the participants for their cooperation. The authors thank Editage for English language editing. 
This study received funding from the Eat, Fun, and Health Association.

\section{Disclosure}

SY received a lecture fee from Ely Lilly, Japan. The authors report no other conflicts of interest in this work.

\section{References}

1. Grundy SM. Metabolic syndrome pandemic. Arterioscler Thromb Vasc Biol. 2008;28(4):629-636. doi:10.1161/ATVBAHA.107.151092

2. Scheen AJ, Van Gaal LF. Combating the dual burden: therapeutic targeting of common pathways in obesity and type 2 diabetes. Lancet Diabetes Endocrinol. 2014;2(11):911-922. doi:10.1016/S22138587(14)70004-X

3. Knowler WC, Barrett-Connor E, Fowler SE, et al. Reduction in the incidence of type 2 diabetes with lifestyle intervention or metformin N Engl J Med. 2002;346(6):393-403.

4. Tuomilehto J, Lindstrom J, Ericksson JG, et al. Prevention of type 2 diabetes mellitus by changes in lifestyle among subjects with impaired glucose tolerance. $N$ Engl $J$ Med. 2001;344 (18):1343-1350. doi:10.1056/NEJM200105033441801

5. Pan XR, Li GW, Hu YH, et al. Effects of diet and exercise in preventing NIDDM in people with impaired glucose tolerance. The Da Qing IGT and Diabetes Study. Diabetes Care. 1997;20 (4):537-544. doi:10.2337/diacare.20.4.537

6. Shai I, Schwarzfuchs D, Henkin Y, et al. Weight loss with a low-carbohydrate Mediterranean, or low-fat diet. $N$ Engl J Med. 2008;359(3):229-241. doi:10.1056/NEJMoa0708681

7. Esposito K, Maiorino MI, Petrizzo M, Bellastella G, Giugliano D. The effects of a Mediterranean diet on the need for diabetes drugs and remission of newly diagnosed type 2 diabetes: follow-up of a randomized trial. Diabetes Care. 2014;37(7):1824-1830. doi:10.2337/dc13-2899

8. Kohro T, Furui Y, Mitsutake N, et al. The Japanese national health screening and intervention program aimed at preventing worsening of the metabolic syndrome. Int Heart J. 2008;49(2):193-203. doi:10.1536/ihj.49.193

9. Japanese Ministry of Health, Labor and Welfare. The standard program of the Specific Health Checkup and Guidance 2018 edition. P1-4. Home page of MHLW; 2018. Available from: https://www. mhlw.go.jp/file/06-Seisakujouhou-10900000-Kenkoukyoku/03.pdf. Accessed February 23, 2021. [in Japanese].

10. Tsushita K, Hosler SA, Miura K, et al. Rationale and descriptive analysis of Specific Health Guidance: the nationwide lifestyle intervention program targeting metabolic syndrome in Japan J Atheroscler Thromb. 2018;25(4):308-322. doi:10.5551/jat.42010

11. Nishizawa H, Shimomura I. Population approaches targeting metabolic syndrome focusing on Japanese trials. Nutrients. 2019;11(6): E1430. doi:10.3390/nu11061430

12. Fukuma S, Iizuka T, Ikenoue T, Tsugawa Y. Association of the National Health Guidance intervention for obesity and cardiovascular risks with health outcomes among Japanese men. JAMA Intern Med. 2020;180(12):1630-1637. doi:10.1001/jamainternmed.2020.4334

13. Stunkard AJ. The current status of treatment for obesity in adults. Res Publ Assoc Res Nerv Ment Dis. 1984;62:157-173.

14. Lustig RH. The neuroendocrinology of childhood obesity. Pediatr Clin North Am. 2001;48(4):909-930. doi:10.1016/S0031-3955(05) 70348-5

15. Noguchi M, Kojima S, Sairenchi T, et al. Japan trial in high-risk individuals to accelerate their referral to physicians (J-HARP) - a nurse-led, community-based prevention program of lifestyle-related disease. $\quad J$ Epidemiol. 2020;30(4):194-199. doi:10.2188/jea. JE20180194
16. Yamada $\mathrm{Y}$, Uchida J, Izumi $\mathrm{H}$, et al. A non-calorie restricted low-carbohydrate diet is effective as an alternative therapy for patients with type 2 diabetes. Intern Med. 2014;53(1):13-19. doi:10.2169/internalmedicine.53.0861

17. Sanada M, Kabe C, Hata H, et al. Efficacy of a moderately low carbohydrate diet in a 36-month observational study of Japanese patients with type 2 diabetes. Nutrients. 2018;10(5):E528. doi:10.3390/nu10050528

18. The Eat, Fun, and Health Association; 2021. Available from: https:// locabo.net/about/. Accessed February 23, 2021. [in Japanese].

19. Hyde PN, Sapper TN, Crabtree CD, et al. Dietary carbohydrate restriction improves metabolic syndrome independent of weight loss. JCI Insight. 2019;4(12):e128308. doi:10.1172/jci. insight. 128308

20. Johnston CS, Tjonn SL, Swan PD, White A, Hutchins H, Sears B. Ketogenic low-carbohydrate diets have no metabolic advantage over nonketogenic low-carbohydrate diets. Am J Clin Nutr. 2006;83 (5):1055-1061. doi:10.1093/ajcn/83.5.1055

21. Harvey CC, Schofield GM, Zinn C, Thornley SJ, Crofts C, Marien FLR. Low-carbohydrate diets differing in carbohydrate restriction improve cardiometabolic and anthropometric markers in healthy adults: a randomized clinical trial. PeerJ. 2019;7:e6273. doi: $10.7717 /$ peerj. 6273

22. Li Z, Heber D. Ketogenic diet. JAMA. 2020;323(4):386. doi:10.1001/ jama.2019.18408

23. Bantle JP, Wylie-Rosett J, Albright AL, et al. Nutrition recommendations and interventions for diabetes-2006: a position statement of the American Diabetes Association. Diabetes Care. 2006;29 (9):2140-2157.

24. Accurso A, Bernstein RK, Dahlqvist A, et al. Dietary carbohydrate restriction in type 2 diabetes mellitus and metabolic syndrome: time for a critical appraisal. Nutr Metab (Lond). 2008;5:9. doi:10.1186/ 1743-7075-5-9

25. Borel AL. Sleep apnea and sleep habits: relationships with metabolic syndrome. Nutrients. 2019;11(11):E2628. doi:10.3390/nu11112628

26. Japanese Ministry of Health, Labour and Welfare. The specimen measurement office; 2021. Available from: https://www.mhlw.go.jp/ stf/seisakunitsuite/bunya/0000098580.html. Accessed February 23, 2021. [in Japanese].

27. Yuceege M, Firat H, Demir A, Ardic S. Reliability of the Watch-PAT 200 in detecting sleep apnea in highway bus drivers. J Clin Sleep Med. 2013;9(4):339-344. doi:10.5664/jcsm.2584

28. Riccardi G, Rivellese AA. Dietary treatment of the metabolic syndrome-the optimal diet. Br J Nutr. 2000;83(Suppl 1):S143-S148. doi:10.1017/S0007114500001082

29. Arnett DK, Blumenthal RS, Albert MA, et al. 2019 ACC/AHA guideline on the primary prevention of cardiovascular disease: a report of the American College of Cardiology/American Heart Association Task Force on clinical practice guidelines. Circulation. 2019;140(11):e596-e646. doi:10.1161/CIR.0000000000000678

30. Feinman RD. Saturated fat and health: recent advances in research. Lipids. 2010;45(10):891-892. doi:10.1007/s11745-010-3446-8

31. Malhotra A. Saturated fat is not the major issue. BMJ. 2013;347: f6340. doi:10.1136/bmj.f6340

32. Siri-Tarino PW, Chiu S, Bergeron N, Krauss RM. Saturated fats versus polyunsaturated fats versus carbohydrates for cardiovascular disease prevention and treatment. Annu Rev Nutr. 2015;35:517-543. doi:10.1146/annurev-nutr-071714-034449

33. Mozaffarian D, Ludwig DS. The 2015 US dietary guidelines: lifting the ban on total dietary fat. JAMA. 2015;313(24):2421-2422. doi:10.1001/jama.2015.5941

34. Saslow LR, Kim S, Daubenmier JJ, et al. A randomized pilot trial of a moderate carbohydrate diet compared to a very low carbohydrate diet in overweight or obese individuals with type 2 diabetes mellitus or prediabetes. PLoS One. 2014;9(4):e91027. doi:10.1371/journal. pone. 0091027 
35. Saslow LR, Daubenmier JJ, Moskowitz JT, et al. Twelve-month outcomes of a randomized trial of a moderate-carbohydrate versus very low-carbohydrate diet in overweight adults with type 2 diabetes mellitus or prediabetes. Nutr Diabetes. 2017;7(12):304. doi:10.1038/s41387-017-0006-9

36. Shah P, Isley WL. Ketoacidosis during a low-carbohydrate diet. N Engl J Med. 2006;354(1):97-98.

37. Chen TY, Smith W, Rosenstock JL, Lessnau KD. A life-threatening complication of Atkins diet. Lancet. 2006;367(9514):958. doi:10.1016/S0140-6736(06)68394-3

38. Iwata H, Tsuzuki S, Iwata M, Terasawa T. Ketoacidosis due to a low-carbohydrate diet in an elderly women with dementia and abnormal eating behavior. Intern Med. 2017;56(19):2671-2675. doi:10.2169/internalmedicine.8689-16

39. Slade S, Ashurst J. Diet-induced ketoacidosis in a non-diabetic: a case report. Clin Pract Cases Emerg Med. 2020;4(2):259-262. doi:10.5811/cpcem.2020.2.44736

40. Muramoto A, Yamamoto N, Nakamura M, Koike G, Numata T, Tamakoshi A. Effect of intensive lifestyle intervention programs on metabolic syndrome and obesity. J Jpn Soc Study Obes. 2010;16 (3):182-187.

41. Jafari-Maram S, Daneshzad E, Brett NR, Bellissimmo N, Azadbakht L. Association of low-carbohydrate diet score with overweight, obesity and cardiovascular disease risk factors: a cross-sectional study in Iranian women. J Cardiovasc Thorac Res. 2019;11(3):216-223. doi:10.15171/jcvtr.2019.36

42. Daneshzad E, Keshavarz SA, Qorbani M, Larijani B, Azadbakht L. Association between a low-carbohydrate diet and sleep status, depression, anxiety, and stress score. J Sci Food Agric. 2020;100 (7):2946-2952. doi:10.1002/jsfa.10322

43. Evert AB, Dennison M, Gardner CD, et al. Nutrition therapy for adults with diabetes or prediabetes: a consensus report. Diabetes Care. 2019;42(5):731-754. doi:10.2337/dci19-0014

44. Guess ND. Dietary interventions for the prevention of type 2 diabetes in high-risk groups: current state of evidence and future research needs. Nutrients. 2018;10(9):E1245. doi:10.3390/nu10091245

45. Shinoda M, Yamakawa T, Takahashi K, et al. Prevalence of obstructive sleep apnea determined by the Watchpat in nonobese Japanese patients with poor glucose control and type 2 diabetes. Endocr Pract. 2019;25(2):170-177. doi:10.4158/EP-2018-0200
46. Araghi MH, Chen YF, Jagielski A, et al. Effectiveness of lifestyle interventions on obstructive sleep apnea (OSA): systematic review and meta-analysis. Sleep. 2013;36(10):1553-1562. doi:10.5665/ sleep. 3056

47. Luca G, Haba Rubio J, Andries D, et al. Age and gender variations of sleep in subjects without sleep disorders. Ann Med. 2015;47 (6):482-491. doi:10.3109/07853890.2015.1074271

48. Yamada S, Yamada Y, Irie J, Hara K, Kadowaki T, Atsumi Y. Societal marketing in the treatment of type 2 diabetes mellitus: a longitudinal questionnaire survey for Michelin-starred restaurants in Japan. Int J Environ Res Public Health. 2019;16(4):E636. doi:10.3390/ ijerph16040636

49. Sakamoto M, Matsutani D, Minato S, et al. Seasonal variations in the achievement of guideline targets for $\mathrm{HbAlc}$, blood pressure, and cholesterol among patients with type 2 diabetes: a nationwide population-based study (ABC Study: JDDM49). Diabetes Care. 2019;42(5):816-823. doi:10.2337/dc18-1953

50. Sato J, Kanazawa A, Makita S, et al. A randomized controlled trial of $130 \mathrm{~g} /$ day low-carbohydrate diet in type 2 diabetes with poor glycemic control. Clin Nutr. 2017;36(4):992-1000. doi:10.1016/j. clnu.2016.07.003

51. Sato J, Kanazawa A, Hatae C, et al. One year follow-up after a randomized controlled trial of a $130 \mathrm{~g} /$ day low-carbohydrate diet in patients with type 2 diabetes mellitus and poor glycemic control. PLoS One. 2017;12(12):e0188892. doi:10.1371/journal. pone. 0188892

52. Haimoto H, Iwata M, Wakai K, Umegaki H. Long-term effects of a diet loosely restricting carbohydrates on HbA1c levels, BMI and tapering of sulfonylureas in type 2 diabetes: a 2-year follow-up study. Diabetes Res Clin Pract. 2008;79(2):350-356. doi:10.1016/j. diabres.2007.09.009

53. Yamada S, Kabeya Y, Noto H. Dietary approaches for Japanese patients with diabetes: a systematic review. Nutrients. 2018;10(8): E1080. doi:10.3390/nu10081080

\section{Publish your work in this journal}

Diabetes, Metabolic Syndrome and Obesity: Targets and Therapy is an international, peer-reviewed open-access journal committed to the rapid publication of the latest laboratory and clinical findings in the fields of diabetes, metabolic syndrome and obesity research. Original research, review, case reports, hypothesis formation, expert opinion and commentaries are all considered for publication. The manuscript management system is completely online and includes a very quick and fair peer-review system, which is all easy to use. Visit http://www.dovepress.com/testimonials.php to read real quotes from published authors.

Submit your manuscript here: https://www.dovepress.com/diabetes-metabolic-syndrome-and-obesity-targets-and-therapy-journal 